3.Patow CA, Pruet CW, Fetter TW. Nasogastric tube perforation of the nasopharynx. South Med J 1985; 78:1362-5.

4. Thair AH, Adriani JA. A method of inserting a nasogastric tube in the anesthetized or comatose patient. Anesth Analg 197I; 50: I79-80.

\section{Ginecologia \\ Qual a CONDUTA ATUAL NA MOLÉSTIA INFLAMATÓRIA PÉLVICA AGUDA?}

Mulher, 19 anos com dor em fossa ilíaca direita há dois dias, em cólica contínua, sem fatores de melhora ou piora, sem associação a alterações de hábito intestinal ou alimentar, mas associada à febre. Sexualmente ativa, sem parceiro fixo, refere início do quadro após fluxo menstrual, e nega emprego de métodos contraceptivos (MC). Tabagista. No momento da admissão no PS, encontrava-se febril $\left(38,1^{\circ} \mathrm{C}\right)$, levemente descorada e desidratada, anictérica e acianótica. $O$ exame físico demonstrava dor à pal pação abdominal, especialmente na região infra-umbilical, com peritonismo na fossa ilíaca direita. $O$ exame ginecológico revelou conteúdo vaginal amarelado, hiperemia cervical, e o toque demonstrava dor à mobilização doútero e espessamento da região anexial direita.

Esta paciente apresenta quadro compatível com moléstia inflamatória pélvica aguda. Independente do perfil demográfico compatível (jovem, multiplicidade de parceiros, tabagista, sem utilização de $M C$ ), está presente 0 quadro clínico que, habitualmente, se inicia a partir do fluxo menstrual, além da dor ao toque associada a espessamento anexial. Febre e comprometimento do estado geral conferem ao quadro intensidade moderada. Os principais diagnósticos diferenciais a serem considerados seriam gravidez ectópica (GE), infecção urinária e apendicite. $\mathrm{Na}$ GE não costuma haver febre ao mesmo tempo em que há atraso menstrual associado a sangramento genital. Não há referência a sintomatologia urinária. A apendicite costuma apresentar associação a quadros gastrintestinais, sem comemorativos no exame ginecológico, sendo o toque retal útil neste diferencial.
Hemograma, leucograma, exame de sedimento urinário e ultra-sonografia pélvica são importantes. A tomografia computadorizada tem demonstrado maior especificidade para apendicite. A videolaparoscopia é tanto diagnóstica como terapêutica, em ambas as situações. $O$ tratamento parenteral poderá ser realizado com cefoxitina 2 g a cada 6 horas, associado a doxiciclina oral $100 \mathrm{mg}$ a cada 6 horas; ou clindamicina $900 \mathrm{mg}$ IV a cada 8 horas MAIS gentamicina IV ou IM $(1,5 \mathrm{mg} / \mathrm{kg})$ MAIS penicilina $G$ cristalina 4 a 5 milhões de unidades IV a cada 4 horas. Não ocorrendo melhora clínica/laboratorial em 48 horas, há necessidade de reavaliação diagnóstica e terapêutica.

\section{Eduardo Vieira da Motta}

\section{Referências}

I. Eschenbach DA; Wölner Hanssen P; Hawes SE; Pavletic A; Paavonen]; Holmes KK. Acute pelvic inflammatory disease: associations of clinical and laboratory findings with laparoscopic findings. Obstet Gynecol 1997; 89: 184-92.

2. Paavonen J. Pelvic inflammatory disease. From diagnosis to prevention. Dermatol Clin 1998; 16:747-56.

\section{Medicina Baseada em Euidências QuANDO INDICAR PROTEÍNA C ATIVADA NA SEPSE GRAVE E CHOQUE SÉPTICO?}

Pacientes portadores de sepse grave e/ou choque séptico apresentam elevada taxa de morbi-mortalidade, boa parte atribuída ao desenvolvimento de disfunção de múltiplos órgãos. Mortalidade esta que se mantinha inalterada, apesar de inúmeros estudos clínicos utilizando novas intervenções medicamentosas. Em 2001, o New England Journal of Medicine publicou o primeiro ensaio clínico com um novo medicamento capaz de reduzir mortalidade nessa população. Trata-se da proteína $\mathrm{C}$ ativada recombinante humana (rhAPC) que, quando infundido endovenosamente por 96 horas, foi capaz de reduzir em $20 \%$ o risco relativo de morte de pacientes com sepse grave. Desde então, outros estudos, bem como a própria prática clínica (o medicamento já foi aprovado em vários países incluindo Brasil), vem nos ensinando exatamente qual o paciente que deve, impreterivelmente, receber o medicamento.

Dados oriundos deste estudo indicavam rhAPC para pacientes que apresentassem os seguintes critérios: a) foco infeccioso bem documentado; b) presença de sinais clínicos e laboratoriais, no mínimo três, de resposta inflamatória sistêmica (taquicardia, taquipnéia, febre e leucocitose); c) presença de, no mínimo, uma disfunção orgânica aguda, secundária ao quadro séptico (cardiovascular, respiratória, renal, hematológica, entre outras). Vale ressaltar que pacientes com sepse grave que apresentassem disfunção cardiovascular (necessidade de drogas vasoativas para estabilizar a pressão arterial) eram considerados portadores de choque séptico. Ainda, segundo esse estudo, são consideradas contra-indicações os pacientes que apresentem qualquer um dos seguintes critérios: a) elevado risco de sangramento (usuários de anticoagulantes, hemofílicos, hepatopatas graves, lesões gastrintestinais ou de sistema nervoso central, entre outras); b) pacientes menores de 18 anos ou com peso superior a $130 \mathrm{~kg} \mathrm{e} \mathrm{c}$ ) pacientes com pobre expectativa de sobrevida, ou pela doença de base ou pela própria sepse.

Conclui-se que pacientes portadores de sepse grave e/ou choque séptico são candidatos ao tratamento com rhAPC, salvo aqueles com contra-indicação formal. Dados mais recentes, e alguns ainda baseados no estudo original, acresceram mais alguns critérios que devem ser observados antes de se iniciar o produto. Primeiro, o medicamento apresenta maior benefício e menor risco em pacientes mais graves (com duas ou mais disfunções orgânicas com escore APACHE II $>25$ ). Segundo, pacientes com acentuada plaquetopenia ou com meningite não devem receber o medicamento, pelo risco aumentado de sangramento intracraniano. Terceiro, a janela terapêutica deve ser rigorosamente seguida. Isto é, o medicamento deve ser iniciado até 48 horas após o início da primeira disfunção orgânica. O médico deve ter certeza de que o paciente está evoluindo com disfunções orgânicas. Portanto, todo 0 tratamento inicial deve ser rápido e agressivo, 
no sentido de reverter os desarranjos fisiológicos, diminuindo, assim, o risco de se evoluir com múltiplas disfunções orgânicas. Por fim, deve-se ressaltar que todo o tratamento disponível para essa população tem que ser adequadamente oferecido e que a rhAPC complementa de forma eficaz, mas não substitui aquilo que temos feito atualmente.

\section{Eliézer Silva}

Luiz francisco Poli de Figueiredo

\section{Referências}

I. Bernard GR, Vincent LL, Laterre PF, La Rosa SP, Dhainaut JF, Lopez - Rodriguez A, et al. Recombinant human protein $C$ worldwide evaluation in severe sepsis (PROWESS) study group. Efficacy and safety of recombinant human activated protein $\mathrm{C}$ for severe sepsis. N Engl J Med 200I; 344:699-709.

2. Bernard GR, Ely EW, Wright T], Fraiz J, Stasek JR, Russell JA, et al. Safety and dose relationship of recombinant human activated protein $\mathrm{C}$ for coagulopathy in severe sepsis. Crit Care Med 2001;29:205I-9.

3. Ely EW, Bernard GR, Vincent JL. Activated protein $C$ for severe sepsis. N Engl J Med 2002;347:1035-6.

\section{Obstetricia}

\section{QuAL É A CONDUTA ATUAL NO ÓBITO FETAL?}

Considerando-se que o produto da concepção se define como feto a partir de 10 semanas de gestação, o óbito fetal (OF) seria toda a morte a partir desta idade gestacional.A Organização Mundial da Saúde define o OF como a "morte do feto antes da completa expulsão ou extração do produto da concepção do corpo da mãe, independente da duração da gravidez". O Centro Nacional de Estatística da Saúde dos Estados Unidos conceitua morte fetal aquela ocorrida a partir de 20 semanas de gestação. Da mesma forma, para acomodar os interesses burocráticos, a maioria das estatísticas nacionais sobre $\mathrm{o}$ assunto preferem defini-lo a partir de 20 semanas de gestação ou peso no nascimento maior que 500 gramas. A incidência é muito variável nos diversos serviços universitários, oscilando entre $0,2 \%$ a $4,5 \%$. Em estudo realizado no
Hospital das Clínicas da FMUSP, Schupp etal., 2000 , observaram incidência de $4,5 \%$ no período de 1993 a 1998. A assistência obstétrica, nesses casos, abarca atenção global à paciente em virtude de envolver intensamente os aspectos emocionais, um luto a ser elaborado. Inclui também a busca da etiologia que se faz necessária, uma vez que existe grande multiplicidade de fatores predisponentes e desencadeantes desse infausto acontecimento. Dessa forma, as perspectivas futuras do provir obstétrico podem ser clarificadas à luz de investigações individualizadas, com respaldo em conhecimentos teóricos/científicos consolidados. Quanto à resolução dos casos, embora $75 \%$ a $90 \%$ das gestantes com diagnóstico de óbito fetal evoluírem para parto espontâneo em duas semanas, poucas pacientes aceitam aguardar passivamente $o$ evento, solicitando ao médico uma conduta ativa para uma abreviação rápida do quadro. Nessa situação, é indispensável ponderar os riscos e os benefícios oriundos de uma intervenção ativa, no intuito de se otimizar os resultados, com mínimas seqüelas, orgânicas e emocionais. A complexidade na resolução reside na eficácia dos métodos disponíveis, pois geralmente 0 OF ocorre durante o segundo ou início do terceiro trimestre da gestação, quando a cérvix está ainda imatura. Em gestantes sem cicatriz uterina prévia e com uma altura uterina de até $26 \mathrm{~cm}$, utilizamos misoprostol $200 \mu \mathrm{g}$ via oral e $200 \mu \mathrm{g}$ via vaginal de ataque e após $200 \mu \mathrm{g}$ via vaginal a cada 4 horas até o parto, com índice de sucesso de $90 \%$ e tempo médio de indução de 17,7 horas com desvio padrão de I4,2 horas. Se a gestante apresentar uma cicatriz uterina prévia, utilizamos o mesmo esquema, porém com a dose de misoprostol pela metade, isto é $100 \mu \mathrm{g}$. Nos casos com idade gestacional mais avançada, constatado por uma altura uterina acima de $26 \mathrm{~cm}$, utilizamos para indução do parto a ocitocina em dosagem semelhante à indução de um parto normal, com tempo médio de indução de 39,9 horas, com desvio padrão de 50,2 horas. Já nos casos em que a paciente apresenta mais de uma cicatriz uterina prévia, temos conduta personalizada para cada caso. Após o parto sempre há a necessidade de avaliar se ainda existem restos ovulares e nos casos em que isso ocorre deve ser realizada a curetagem uterina. Nos casos em que se adota a conduta expectante, é importante a monitorização de coagulopatia, um evento que aparece na incidência de até $25 \%$ após quatro semanas do óbito.

\section{Tânia Regina Schupp \\ Seizo Miyadahira Marcelo Zugaib}

\section{Referências}

I. Chiswick ML. Commentary on current World Health Organization definitions used in perinatal statistics. Br JObstet Gynaecol I986; 93:1236-8.

2. Tricomi V, Kohl SG. Fetal death in utero. Am J Obstet Gynecol 1957; 74:1092-7.

3. Bugalho A, Bique $C$, Machungo F, Faundes A. Induction of labor with intravaginal misoprostol in intrauterine fetal death. Am JObstet Gynecol 1990; 163:540-2.

4. Schupp TR, MiyadahiraS, KahhaleS, Zugaib $M$. Management of pregnancy in a university hospital: a 6-year study. Rev Hosp Clin Fac Med São Paulo 2000; 55:137-44.

5. Zugaib M, Bittar RE. Protocolos Assistencias da Clínica Obstétrica da Faculdade de Medicina da Universidade de São Paulo. São Paulo: Atheneu; 1996. p. 189-9I.

\section{Pediatria \\ O QUE DEVO OBSERVAR NA REINDICAÇÃo DE TERAPÊUTICA ANTIMICROBIANA?}

$O$ uso de antimicrobiano deve ser observado no que diz respeito ao efeito de seleção e da disseminação dessa seleção de cepas com características especiais. Hoje, os agentes bacterianos que produzem $\beta$ Lactamase (PBL) merecem atenção especial, pois limitam 0 tratamento antimicrobiano. A terapêutica empírica inicial, em muitas circunstâncias, deve ser repensada com base nos dados da história de uso de antimicrobiano pelo paciente. Assim é que acumulam-se na literatura evidências a partir de que, introduzida uma droga $\beta$ Lactâmica em um grupo de pacientes, rapidamente (ao fim da I ${ }^{\text {a }}$ semana) em $50 \%$ deles serão detectadas cepas $\mathrm{PBL}$, quando antes do uso do antibiótico 